\title{
Sustainable regeneration of urban areas (using the example of Moscow renovation program)
}

\author{
Vladimir Rimshin ${ }^{1, *}$, and Roman Aralov ${ }^{1}$ \\ ${ }^{1}$ Moscow State University of Civil Engineering (National Research University), 26 Yaroslavskoe \\ shosse, Moscow, 129337, Russian Federation
}

\begin{abstract}
The paper discusses advantages and disadvantages of the renovation program in the city of Moscow (Russia). This program of the Moscow government is aimed at demolishing low-rise housing built in the 1960s and new construction in the vacated territory. On the basis of the analysis of this program's disadvantages, seven major problems were identified - a flaw in the socio-spatial model of the city, a threat to small and medium businesses, a mortgage crisis, an economic issue, a low level of apartment comfort, an environmental problem, and increase in population density. Various methods for the reconstruction of the fivestory buildings of the first mass series with superstructure floors are considered.
\end{abstract}

\section{Introduction}

The renovation program in Moscow is a program of the low-rise buildings' demolition, which the operational period is coming to an end, and the construction of new modern houses in the vacated territories. These low-rise buildings are named «Khrushchevki», they were built from 1957 to 1968.

It was originally planned to demolish about 7.9 million buildings with a total area of 25 million square meters, where lived 1.6 million people, and build about 35.14 million square meters. But the list of demolished houses was reduced at the beginning of this year, the final number and location of the demolished houses is presented in Figure 1 [1].

\footnotetext{
*Corresponding author: v.rimshin@niisf.ru
} 


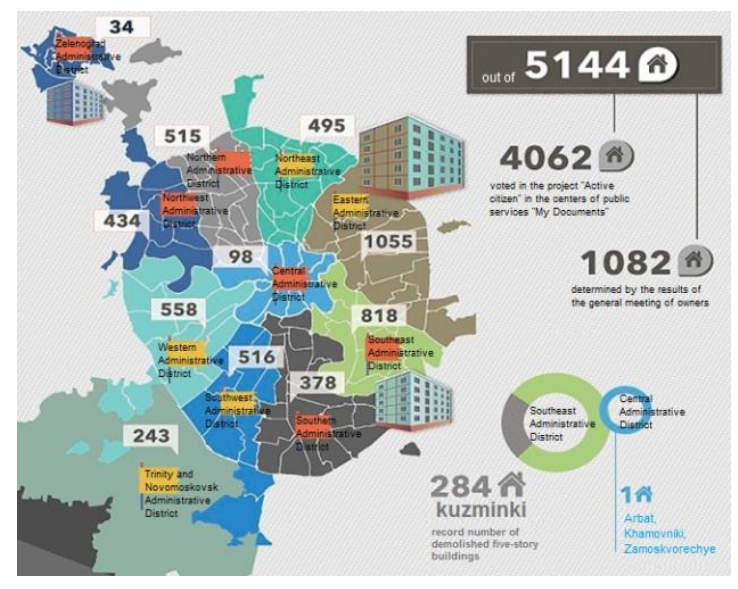

Fig. 1. Buildings included in the renovation program.

It is assumed that these buildings tenants will be relocated to new houses in the same or nearby area, to apartments with the same number of rooms. At the same time, the living area should be the same or larger than in previous apartments, and the total area is strictly larger. Increases in the total area are achieved through large corridors, kitchens, and toilets. The program provides for the provision of an equivalent area in another house or a refund of the cost of the previous room for non-residential premises owners.

This program will allow many people to improve their living conditions, move from communal apartments and emergency houses to new apartments. In this regard, it was assumed that this program will be perceived positively by Muscovites. However, not all residents in these houses were satisfied with this program [2].

\section{Results}

Why did this program cause an incomplete understanding among some residents, because the program is important and useful for the city? The shortcomings of this program were considered in detail based on the opinions of ordinary residents in Moscow, builders, journalists and public figures. Five main reasons for discontent of Muscovites were identified:

1) Failure of the program of socio-spatial city model.

When implementing such a colossal program, a spatial city transformation should be developed in parallel. If a new high-rise house is built on the site of an old five-story building, then the transport situation will be worse. It will be much more difficult to drive up to the house or yard. New kindergartens, schools, shops, etc. should also be provided with the increase in the number of new residents. It is unlikely that existing public places will have enough space for everyone. And this in turn will lead to new state spending, and there is a need for land for the construction new schools and kindergartens, which, but there is not enough land in Moscow [3].

2) The threat to small and medium businesses

The Moscow Chamber of Commerce and Industry announced that about two thousand small and medium-sized businesses were included in the renovation program.

According to the renovation program, entrepreneurs who own non-residential premises in buildings intended for demolition can choose between obtaining equivalent premises in another building or receiving monetary compensation after assessing the market value. 
It should be understood that the territorial location determines the basic guarantee of success and survival for most establishments (hairdressing, pharmacies, shops, etc.). And the program does not give any guarantee that equivalent premises will be located in the same district.

3) Ecological problem

A large amount of garbage will be generated (about 60 million tons) during the demolition of the five-story building. According to the authorities, all garbage will be recycled, but no processing plant has been built yet.

It is assumed that old brick, concrete and reinforcement will be used in the construction of foundations and roads. At the same time, it was stated that the sites for the processing of such waste would be arranged directly on the construction sites. It is necessary to understand that it will produce a large number of small particles that will pollute the air.

It was declared that the existing trees will not be cut down, but it is difficult to believe, because the trees will be a serious obstacle for new construction. Therefore, the number of green spaces of the city (and without that scanty) will significantly decrease. Environmentalists estimate that the city will lose about 27 million $\mathrm{m} 2$ of green space $(7 \%)$ in the old borders of Moscow in the process of renovation of houses; it is terrible that in some areas this figure can reach $50 \%$ [4].

4) Low comfort of new apartments

- Location of new buildings

Residents that participate in the program fear that the accommodation provided to them will not correspond to the previous living conditions. People understand that they are unlikely to be offered good-quality housing, which is located in areas adjacent to the central part of the capital. Even with an equal number of squares of living space or a higher cost, housing may be located in a less comfortable area or an environmentally unfavorable area.

There are almost no free spots in residential areas, so it is not surprising if houses for immigrants will be located in industrial zones, Russian Railways technical zones, under power lines and other areas that are unfavorable for life.

It became known that about 50 million $\mathrm{m} 2$ of real estate will be built in industrial zones. At the same time, the industrial zone density is increased from a maximum of ten thousand $\mathrm{m} 2$ to fifteen thousand $\mathrm{m} 2$ per 1 ha.

- new housing safety

Despite the same size, new buildings quality can be very mediocre. People are afraid that builders use cheap construction and finishing materials, there will be inconvenient layout of apartments on the floor or rooms in apartments.

And their fears are not groundless - for example, in August 2018, a ceiling collapsed in a new building at Pyatnitskoe Shosse, 21, people were injured. As it turned out later, this is not the only case - apparently, the technology was violated during the construction work. The developer of this house was Pioneer Group, which, in addition to this house, transfers to Moscow $600,000 \mathrm{~m} 2$ of housing for the renovation program implementation.

The first houses, which began to enter the renovation program, were actually redesigned and adapted to the renovation standard. That is why everything turned out not to the full. It was promised that by the end of 2020 the first house will be built, completely designed and built according to the standards of the renovation program [5].

- new apartments comfort

People do not understand why they need to move from a sturdy brick five-story building with quality and expensive repairs where they do not know. It is stated that proposed apartments will be provided with a full finish, as the flooring - linoleum or laminate, wallpaper - for painting, kitchens and bathrooms are tiled. Regardless of this, with a high degree of probability, most people will still do repairs - people have quite different taste 
(and quality) preferences for their housing, therefore not everyone are satisfied with "typical" repairs.

The first starting house for settlement was declared on 5th Parkovaya Street 62B. According to reviews of new tenants, two-room apartments layout is not quite comfortable and safe. So, access to the balcony is carried out from a small room, and since usually these rooms in the family are reserved for children, this layout is not sufficiently developed.

5) Increase in population density

The population density is planned to be increased for fifteen times: the new development assumes a population density of 20,000 people per hectare, and the existing development - 1,300 people per hectare.

According to the existing city norms, it is allowed to increase the building density on the released sites no more than 2.5-3 times. Currently, Khrushchev houses occupy 8-10 thousand $\mathrm{m} 2$ / ha, according to the allowed standard, this area can be built up with houses with an area of 20-30 $\mathrm{m} 2$ / ha. There is no doubt that developers will focus on the upper limit of this standard in conditions of high prices for land in the central areas of the city.

This program is not new, people engaged in the Khrushchev demolition in the 90s. Then, about 21 million $\mathrm{m} 2$ of new housing was erected on the site of 6.1 million $\mathrm{m} 2$ of five-story buildings. It is easy to calculate that even then the compaction was carried out with a coefficient of $3.3 \%$.

Nowadays, the population density is quite significant and is comparable with the similar indicators in large cities in Europe and North America. Moscow is a city with fairly dense traffic, although a lot of things has been done and is being done in this direction [6].

Is there a way to avoid the above problems? An alternative to the renovation program may be the reconstruction of five-story buildings. Not everyone knows that there is a law that allows five-story buildings reconstruction by means of superstructure in Moscow since 2014. It is not about emergency buildings, of course, but about fairly strong brick and panel five-story buildings. At the same time, reconstruction works are carried out without relocation, the area of houses and apartments increases, while residents continue to live in familiar areas, there is no need to change work and schools / kindergartens for children.

A building should be appropriate to the following criteria in order to participate in the reconstruction program: number of floors - no more than five floors; the object belongs to a group of brick (block) houses, built in 1950-1965; factory prefabricated reinforced concrete floors; ceiling height is about 3 meters; the estimated depreciation for the current year is not more than $50 \%$; the number of apartments should not exceed 40 .

This program unprofitability was the absence or insufficient design solutions elaboration. Homeowners make reconstruction on their own, and in addition to residents' contributions, various funds may be attracted, rent or sale of land owned by the house, various kinds of credit programs. If the residents act as financial participants in the project themselves, then they have the opportunity to purchase new apartments at a construction cost, or even get them for free if the sale of the upper floors exceeds the costs for reconstruction and brings profit [8].

Why is reconstruction more profitable than new construction from an economic point of view?

- the life of five-story buildings with timely repairs can reach about 120 years, since the main part of buildings has reinforced concrete slabs and little worn bearing structures. A building will lose its value during demolition, so it is expressed by the residual value of the elements. Having examined a five-story building with a service life of about 60 years, bearing elements with a service life of about 100 years will be demolished. That is, about $50 \%$ of the total cost of a five-story residential building will disappear.

- demolishing cost, transportation and disposal garbage is about $35-40 \%$ of a new 5 -storey building cost 
- it is necessary to resettle tenants.

- reconstructed housing will meet increased comfort conditions, it will be possible to get additional living space (by average, up to 30 additional meters) [9].

Independent superstructure of the building. The building expands on each side, thereby increasing floors of the building. Due to this technology a new foundation is built around the perimeter of the house, outside the area of the compressible stratum of the basement. Bored piles, on which superstructure framework will later be supported, act as a foundation. The schematic diagram of this superstructure is presented in Figure 2.

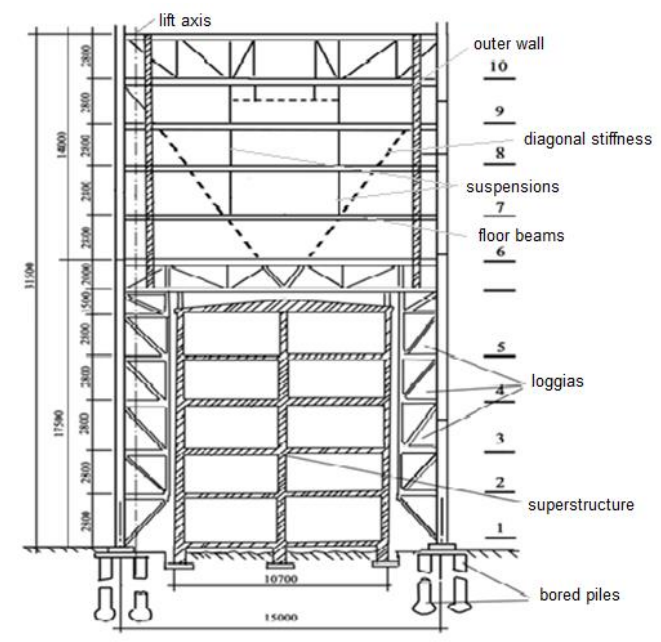

Fig.2. The scheme of independent adjustment of the five-story building.

Superstructure by the method of Professor S. N. Bulgakov. This method technology supposes that a new part is attached to the existing building. Then, a common monolithic slab is arranged over these parts of the house, and on one side, along the entire length of the old part, pylons are mounted on an independent foundation, between which bay windows or loggias can be placed. Further an upper superstructure is mounted along this slab. The schematic diagram of this method is presented in Figure 3.

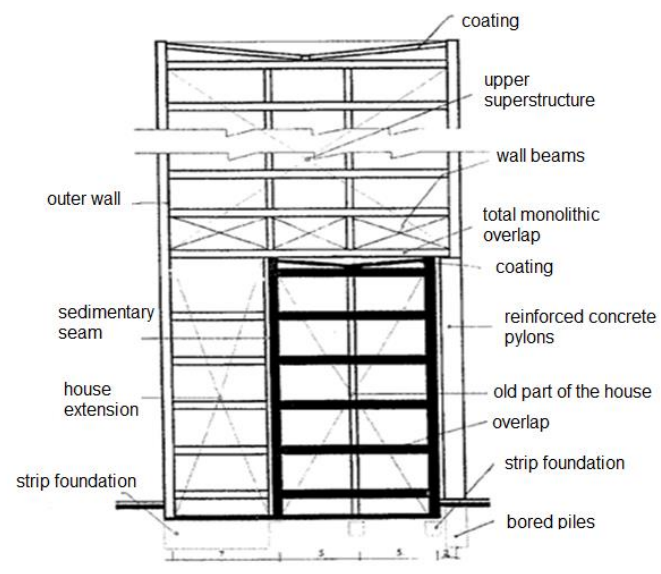

Fig.3. Setup scheme by the method of Professor S. N. Bulgakov

Professor E. Matveyev proposed the following method for the reconstruction: volumes are attached to the facades, and the setting is performed. In this case, loads from the 
superstructured part and the joint operation of the attached volumes with the old part are carried out with reinforced concrete belts with prestressed reinforcement. Monolithic belts are arranged at the level of coverage along the perimeter of the exterior and interior walls. The schematic diagram of the superstructure is shown in Figure 4 [10].

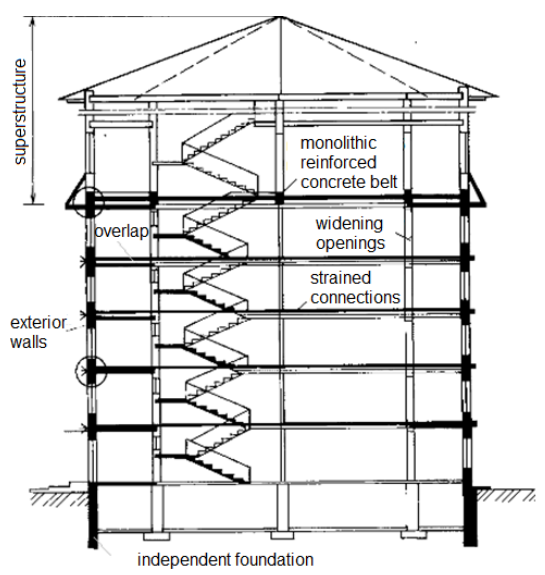

Fig.4. Configuration scheme by the method of Professor E.P. Matveyev

Setting up the building will not only save the house, but also extend its life cycle. At the same time, the building becomes taller and wider, elevators, refuse chutes appear in it, and the area of apartments in the house increases to $25 \%$.

In Moscow, you can get acquainted with successful examples of such reconstruction's implementation. At the beginning of the 2000s, on Marshal Zhukov Avenue, one of the five-story buildings was reconstructed into a seven-story house without removal. A complete repair was carried out, engineering communications were replaced, an elevator and a garbage dump appeared.

Another renovated house is located at Mishina Str., 32. The reconstruction also took place without the resettlement. Nowadays the premium housing is located at the place of usual Khrushchev. Each apartment received at the same extra room. There is an example of a five-story building reconstruction on Khimki Boulevard, 4 in Figure 5.
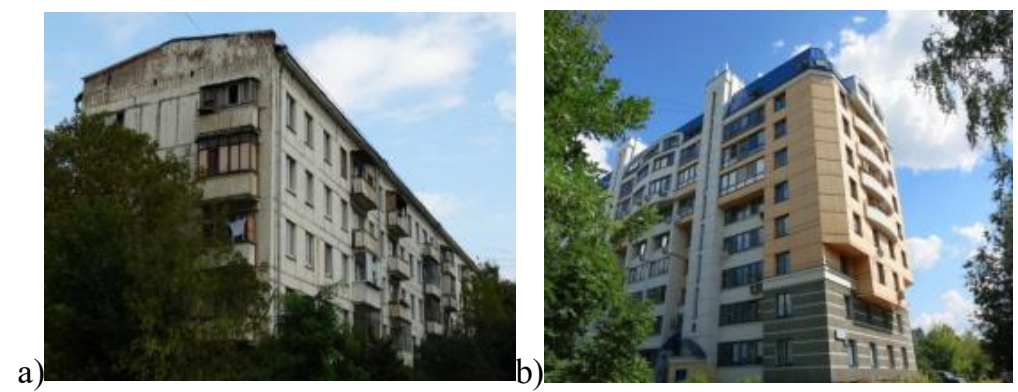

Fig. 5. Residential building at Khimkinsky Boulevard, 4: a) before reconstruction b) after reconstruction

The existing building series I-515, was built in 1965. Characteristics of the building, before and after the reconstruction are given in table 1.

Table 1. House characteristics on Khimkinsky Boulevard, 4 before and after reconstruction

\begin{tabular}{|c|c|c|}
\hline Index & Before reconstruction & After reconstruction \\
\hline total area & $5400 \mathrm{~m}^{2}$ & $13343 \mathrm{~m}^{2}$ \\
\hline
\end{tabular}




\begin{tabular}{|c|c|c|}
\hline $\begin{array}{c}\text { total area of } \\
\text { apartments }\end{array}$ & $4460 \mathrm{~m}^{2}$ & $9636 \mathrm{~m}^{2}$ \\
\hline $\begin{array}{l}\text { Number of } \\
\text { apartments }\end{array}$ & $\begin{array}{l}10 \text { one-room }\left(31-32 \mathrm{~m}^{2}\right) \text {, } \\
75 \text { two-room }\left(40-45 \mathrm{~m}^{2}\right) \text {, } \\
15 \text { three-room }\left(54-58 \mathrm{~m}^{2}\right)\end{array}$ & $\begin{array}{c}31 \text { one-room }\left(47-48 \mathrm{~m}^{2}\right), \\
38 \text { two-room }\left(76-81 \mathrm{~m}^{2}\right), \\
38 \text { three-room }\left(109-127 \mathrm{~m}^{2}\right), \\
11 \text { four-room }\left(95-176 \mathrm{~m}^{2}\right), \\
4 \text { five-room }\left(157-172 \mathrm{~m}^{2}\right)\end{array}$ \\
\hline Number of floors & 5 & 9 \\
\hline Kitchen area & $7 \mathrm{~m}^{2}$ & $10-12 \mathrm{~m}^{2}$ \\
\hline
\end{tabular}

In addition, elevators, refuse chutes and glazed balconies appeared in the building. As a new facade, a ventilated facade with insulation was chosen (the saving of heating costs was $40 \%$ cheaper from each apartment). The layout of the modified building is shown in Figure 6.

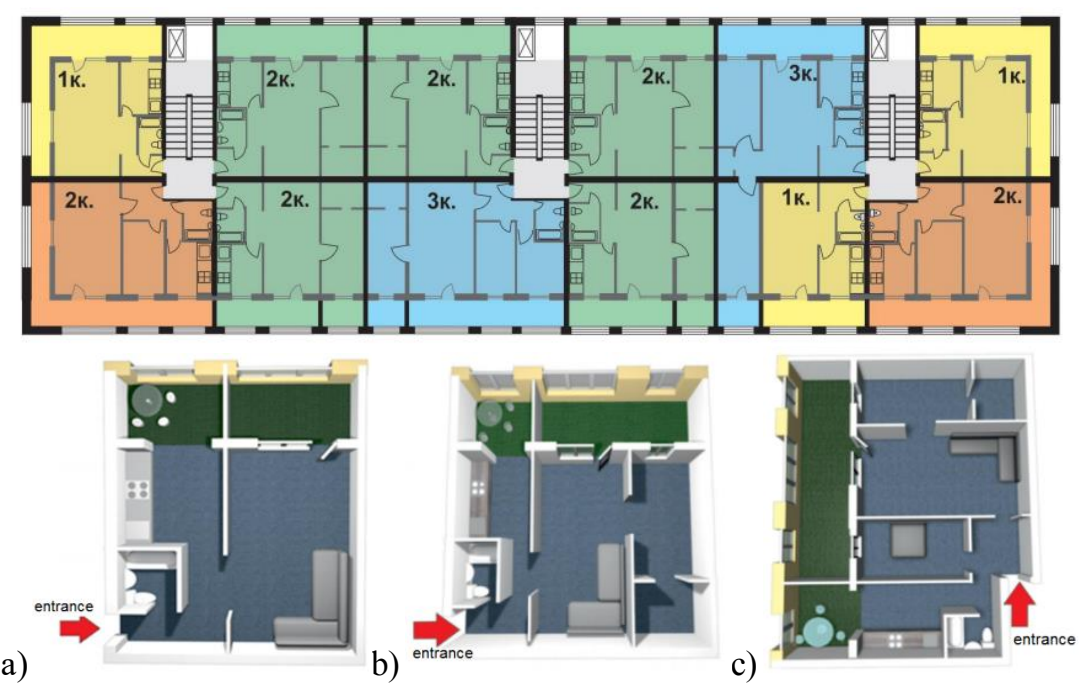

Fig. 6. Apartment layouts; a) one-room apartment, b) two-room, c) three-room

The market value of the apartments in the house increased by almost $40 \%$ after the reconstruction. So, the price of a two-room apartment was about 7 million rublesbefore the reconstruction, and this apartment was already worth 10.5 million rubles after reconstruction [11].

Thus, there is no doubt about the advisability of modernizing and reconstructing fivestory buildings, since it allows efficient use of urban land resources, builds new housing in the built-up area, improves living comfort, reduces heating costs, and allows for physically and morally outdated residential buildings modern look.

\section{Conclusions}

Of course, the renovation program will help ridding the city of dilapidated emergency buildings. Apartment owners in five-story buildings that are really impossible to renovate will receive new housing, as well as room owners in communal apartments will be able to get separate housing. And it is a significant improvement in housing conditions.

But, there are a lot of five-story buildings that should be reconstructed. According to expert estimates, the cost of renovating five-story buildings is $10-15 \%$ lower than the cost 
of building new houses with the same parameters. And reconstructed houses can be much more convenient than new monolithic houses that are proposed to be built in these areas.

In East Germany, about 22 thousand houses were reconstructed, and it is about 2180000 apartments. Renovated houses meet all safety and comfort requirements and existing energy efficiency standards [12]. There are several hundred houses in Moscow that can be reconstructed. And it is necessary, because old buildings are not only the history of our country, but also the history of many generations.

\section{References}

1. V. M. Kretova, V. Yu. Amelin, O. A. Apalkova, D. B. Borisov, Collection of scientific articles, The Future of Science 2 (2013)

2. V. Telichenko, V., Rimshin, V., Eremeev, V., Kurbatov, V. MATEC Web of Conferences 196, 02025 (2018)

3. Varlamov, A.A., Rimshin, V.I., Tverskoi, S.Y. IOP Conference Series: Earth and Environmental Science 177(1), 012040 (2018)

4. V. Rimshin, et al. ARPN Journal of Engineering and Applied Sciences 13(11), 38513856 (2018)

5. E. Kuzina, E., Rimshin, V. Advances in Intelligent Systems and Computing 692, 410$416(2018)$

6. E. Kuzina, E., Cherkas, A., Rimshin, V. IOP Conference Series: Materials Science and Engineering 365(3), 032053 (2018)

7. V. Erofeev, V.T. Research Journal of Pharmaceutical, Biological and Chemical Sciences 7(3), 2506-2517 (2016)

8. Y.M Bazhenov, et al. Engineering Solid Mechanics 4(4), 219-225 (2016)

9. V. Erofeev, et al. Solid State Phenomena 871, 28-32 (2016)

10. A. Krishan, et al. Procedia Engineering 117(1), 211-217 (2016)

11. A. Varlamov, IFAC-PapersOnLine 51(30), 808-811 (2018)

12. I.L. Shubin, et al. Engineering Solid Mechanics, 5(2), 139-144 (2017) 